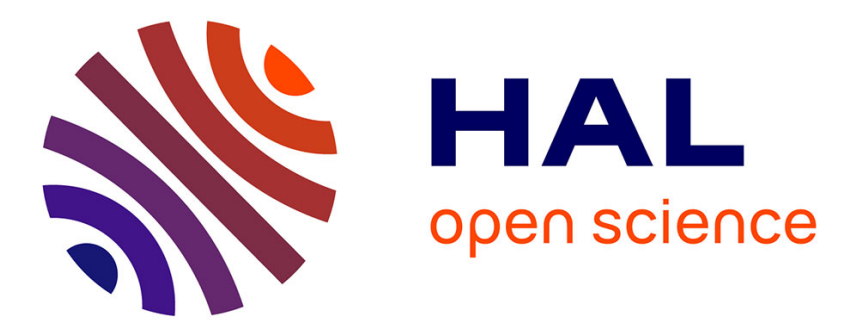

\title{
The impact of photosynthesis on initiation of leaf senescence
}

\author{
Anja Krieger-Liszkay, Karin Krupinska, Ginga Shimakawa
}

\section{To cite this version:}

Anja Krieger-Liszkay, Karin Krupinska, Ginga Shimakawa. The impact of photosynthesis on initiation of leaf senescence. Physiologia Plantarum, 2019, 166 (1), pp.148-164. 10.1111/ppl.12921 . hal02397915

\section{HAL Id: hal-02397915 \\ https://hal.science/hal-02397915}

Submitted on 6 Dec 2019

HAL is a multi-disciplinary open access archive for the deposit and dissemination of scientific research documents, whether they are published or not. The documents may come from teaching and research institutions in France or abroad, or from public or private research centers.
L'archive ouverte pluridisciplinaire HAL, est destinée au dépôt et à la diffusion de documents scientifiques de niveau recherche, publiés ou non, émanant des établissements d'enseignement et de recherche français ou étrangers, des laboratoires publics ou privés. 
1 The impact of photosynthesis on initiation of leaf senescence

2

3 Anja Krieger-Liszkay ${ }^{1, *}$, Karin Krupinska ${ }^{2}$, Ginga Shimakawa ${ }^{1}$

4

5 Institute for Integrative Biology of the Cell (I2BC), Commissariat à l'Energie Atomique et aux

6 Energies Alternatives (CEA) Saclay, Institut de Biologie et de Technologie de Saclay, Centre National

7 de la Recherche Scientifique (CNRS), Université Paris-Sud, Université Paris-Saclay, F-91198 Gif-sur-

8 Yvette cedex, France

$9 \quad{ }^{2}$ Institute of Botany, University of Kiel, Olshausenstraße 40, D-24098 Kiel, Germany

10

11 *Author for correspondence: Anja Krieger-Liszkay; e-mail anja.krieger-liszkay@cea.fr

12

13

\section{Abbreviations}

15 ABA, abscisic acid; CP, chlorophyll binding protein; Cyt, cytochrome; Fd, ferredoxin; FNR, Fd$16 \mathrm{NADP}^{+}$reductase; JA, jasmonic acid; LHC, light-harvesting complex; PS, photosystem; NDH, $17 \mathrm{NAD}(\mathrm{P}) \mathrm{H}$ dehydrogenase; $\mathrm{PQ}$, plastoquinone; PTOX, plastid terminal oxidase; ROS, reactive oxygen 18 species; SA, salicylic acid; SOD, superoxide dismutase

19 
Abstract

Senescence is the last stage of leaf development preceding the death of the organ, and it is important for nutrient remobilization and for feeding sink tissues. There are many reports on leaf senescence but the mechanisms initiating leaf senescence are still poorly understood. Leaf senescence is affected by many environmental factors and seems to vary in different species and even varieties of plants, which makes it difficult to generalize the mechanism. Here, we give an overview on studies reporting about alterations in the composition of the photosynthetic electron transport chain in chloroplasts during senescence. We hypothesize that alternative electron flow and related generation of the proton motive force required for ATP synthesis become increasingly important during progression of senescence. We address the generation of reactive oxygen species (ROS) in chloroplasts in the initiation of senescence, retrograde signaling from the chloroplast to the nucleus and ROS-dependent signaling associated with leaf senescence. Finally, differences between natural senescence and dark-induced senescence are pointed out and a few ideas for increasing crop yields by increasing the chloroplast lifespan are presented.

\section{Introduction}

Photosynthesis is the basis for primary biomass production, and photosynthesis in all green tissues is needed to feed sink tissues like roots, developing organs or specialized storage organs. Senescence is the last stage of leaf development preceding the death of the organ. During senescence valuable compounds are remobilized and nutrients are transported into sink tissues. In crops, photosynthesis especially in flag leaves is known to substantially contribute to the filling of grains and hence to the productivity of cereals (Stoy, 1963; Stamp and Herzog, 1976; Gregersen et al. 2013). Chloroplasts are the main source of carbon- and/or nitrogen-recycling in plants because they contain the majority of nutrients; chloroplastic proteins account for $75 \%$ to $80 \%$ of total the leaf nitrogen in $\mathrm{C}_{3}$ plants (Makino, 2003). Senescence is hence of pivotal importance for plant yields, and premature senescence during stress situations limits yield. The onset of senescence is modulated by external and internal factors like day length (Keskitalo et al. 2005; Fracheboud et al. 2009), temperature (Fracheboud et al. 2009), metabolic status of the leaf, redox homeostasis, epigenetic modifications etc.; and is induced or accompanied by changes in gene expression, especially in the expression of genes encoding transcription factors together with post-transcriptional and post-translational modifications. Senescence is accompanied by a decline of chlorophyll, modifications of the 
photosynthetic apparatus and the generation of reactive oxygen species (ROS) which may be an important trigger for the initiation of specific senescence-relevant processes.

Although it is obvious that chloroplasts are not only the major targets of senescence associated degradation processes, and the declines in photosynthetic activity is an early event in senescence (Krupinska, Humbeck, 2004), the importance of chloroplast signalling in regulation of senescence has been hitherto underestimated in research on senescence regulation. Studies on the sequence of senescence associated process with the model plant Arabidopsis thaliana (Hensel et al. 1993) and with flag leaves of barley collected in the field (Humbeck et al. 1996) clearly showed that the decline in photosynthetic activity precedes the upregulation of the expression of major senescence-associated genes. This suggests, as it has been proposed already in the early $1990^{\text {th }}$ by Hensel and co-workers (Hensel et al. 1993), that nuclear gene expression is controlled by signals originating from chloroplasts, indicating a retrograde control over senescence regulation.

The disassembly of the photosynthetic apparatus during senescence is a developmental phase with a high probability of ROS production caused by changes of the organization of the photosynthetic complexes and changes in electron transport pathways. Although there is very good evidence for the importance of ROS during senescence in many species (Pintó-Marijuan and Munné-Bosch, 2014), the exact sites and mechanisms of light-dependent ROS generation are unknown. In the light, the chloroplast is recognized as the most important site of ROS generation (Laloi and Havaux, 2015). Beside the chloroplasts, other cell compartments like mitochondria, peroxisomes and specialized enzymes, like e.g. the NADPH oxidase at the plasma membrane, also contribute to the overall ROS load.

In this review, we focus mainly on changes in the photosynthetic apparatus and electron transport during early stages of senescence and on related ROS generation in the chloroplast. Darkinduced senescence is not covered.

\section{Alteration of photosynthesis during senescence}

In leaves photosynthetic activity is highest at the mature stage of the leaf and declines gradually during senescence (Stoddart and Thomas, 1982; Fischer and Feller, 1994). Loss of chlorophyll is the most obvious parameter of senescence although the loss of individual compounds of the photosynthetic electron transport chain has been shown to precede chlorophyll loss (see e.g. Humbeck et al. 1996; Schöttler, Tóth, 2014). In other words, one characteristic feature of senescence is the remodeling of the photosynthetic electron transport chain induced by changes in the protein 
composition of the photosynthetic apparatus (Park et al. 2007; Sakuraba et al. 2012a; Nath et al. 2013; Schöttler et al. 2017).

\section{2.a The photosynthetic apparatus}

In mature leaves, the photosynthetic apparatus is situated in the thylakoid membrane of the chloroplasts and it is composed of a number of pigment/protein complexes (Fig. 1). Two photosystems (PSII and PSI) are central for the photosynthetic electron transport on the thylakoid membrane in chloroplasts. The PSII reaction center is often referred to as the complex of the cofactor carrying subunits, D1 and D2, together with cytochrome (Cyt) $b_{559}$, which associates with the other large core subunits PsbB (CP47) and PsbC (CP43). The PSII core complex is associated with the light-harvesting complex (LHC) of PSII, i.e. LHCII, trimers, contains altogether about 27 subunits and is mainly located in the internal part of the grana stacks of the thylakoid membranes. Additionally, the monomeric LHCB is located between the core subunits of PSII and the LHCII trimers (Caffarri et al. 2014). Different to the PSII-LHCII complex, PSI is located in the stroma-exposed membranes, which are the last layers of the grana (margins) and the stroma lamellae. Based on the model by Caffarri et al. (2014), PSI is composed of $~ 15$ subunits, including the PsaA and PsaB, the core subunits forming the PSI reaction center, and the monomeric LHCA. Light energy absorbed by the antenna chlorophyll in PSII and PSI is transferred to reaction center chlorophylls (P680 in PSII and P700 in PSI) where charge separation takes place resulting in the formation of the primary charge pair and initiating electron transport reactions (Fig. 1A). At the oxygen evolving complex $\left(\mathrm{Mn}_{4} \mathrm{CaO}_{5}\right.$ cluster) on the donor side of PSII water is oxidized and oxygen is released. At the acceptor side of PSII plastoquinone (PQ) is reduced to plastoquinol diffuses to the PQ pool and is replaced at PSII by an oxidized PQ. Plastoquinol is oxidized by the Cyt $b_{6} f$ complex which reduces in the so-called high potential chain plastocyanin, the electron donor of PSI, and which pumps protons via the so-called low potential chain and the Q-cycle. At the acceptor side of PSI ferredoxin is reduced that is the substrate of the ferredoxin $\mathrm{NADP}^{+}$oxidoreductase (FNR) reducing $\mathrm{NADP}^{+}$to NADPH. During linear electron transport a proton gradient is established across the thylakoid membrane which provides the driving force for ATP synthesis by the chloroplast ATP synthase. In the chloroplast stroma s, ribulose 1,5bisphosphate (RuBP) carboxylase/oxygenase (Rubisco), catalyzes the carboxylation or oxygenation of RuBP to produce 3-phosphoglycerate, which drives the Calvin-Benson cycle using NADPH and ATP produced by photosynthetic electron transport. Additionally, 2-phosphoglycolate generated in the 
oxygenation reaction of Rubisco is metabolized to RuBP in photorespiration using both reduced

116 ferredoxin and ATP provided by photosynthetic electron transport.

117 Beside linear electron transport, alternative electron transport pathways do exist (Fig. 1B).

118 Reverse electron flow can take place via reduced ferredoxin using the Cyt $b_{6} f$ complex or the NDH

119 complex as electron input module. Cyclic electron flow can take place via two distinct pathways, the

120 first one involving a ferredoxin quinone oxidoreductase, the second one the chloroplast $\mathrm{NAD}(\mathrm{P}) \mathrm{H}$

121 dehydrogenase (NDH) complex, a homolog of the NADH dehydrogenase (complex I) in the

122 respiratory chain in mitochondria. Cyclic electron flow around PSI permits additional proton pumping

123 and is required to optimize the NADPH/ATP ratio. Similar to cyclic electron flow the so-called

124 Mehler reaction, using oxygen as electron acceptor at the acceptor side of PSI, leads to additional

125 proton pumping (Allen 2003). In the chlororespiratory pathway, a light-independent pathway, electron

126 transport takes place from $\mathrm{NAD}(\mathrm{P}) \mathrm{H}$ via the $\mathrm{NDH}$ complex or the Cyt $b_{6} f$ complex and reduces

127 plastoquinone to plastoquinol which is then oxidized by the plastid terminal oxidase (PTOX), a non-

128 heme diiron carboxylate enzyme (Bennoun 2005). In the mature leaf, alternative electron pathways are

129 secondary, but they may become more important during the dismantling of the photosynthetic

130 apparatus during senescence. During senescence the structural alterations of the photosynthetic

131 apparatus, the reorganization of the membrane system within the plastid and the transport processes

132 required for nutrient remobilization are highly energy demanding so that alternative electron transport

133 processes leading to the generation of a proton motif force and ATP synthesis may be of pivotal

134 importance.

\section{2.b Dismantling of the antenna}

137 Different scenarios, that may be species-dependent, have been reported for the dismantling of

138 LHC during senescence. In common to all described events is a loss of the chlorophyll content during

139 senescence. In many species a decrease in the chlorophyll $a / b$ ratio, indicating earlier loss of the

140 reaction centers than of LHCII which dominantly harbors chlorophyll $b$, has been observed, e.g. for

141 rice (Oryza sativa L. cv. Sasanishiki; Hidema et al. 1991), Arabidopsis thaliana (Nath et al. 2013),

142 aspen (Populus tremula; Keskitalo et al. 2005), tobacco (Nicotiana tabacum; Schöttler et al. 2017). In

143 contrast, in barley (Hordeum vulgare), cv. Lomerit, the chlorophyll $a / b$ ratio consistently increased

144 during the progressing of senescence, and the LHCII proteins were upon the first proteins that were

145 degraded during senescence (Krupinska et al. 2012). These examples show that the order of

146 dismantling of the antenna in the processes during senescence may differ between species and that it is 
147 impossible, at least at the current state of knowledge, to put into a universal scheme of events that 148 occur in a definite order during senescence. Further, in barley the abundances of LHCB4 (CP29) and 149 LHCA2 (LHCI) are controlled by light and decrease in response to high light during senescence in the 150 field or under controlled environmental conditions. When during senescence the irradiance was high, 151 abundance was low. When, the senescence process was reversed/retarded by low irradiance (rainy 152 days), abundance of the complexes was observed to be high again (Humbeck and Krupinska 2003).

153 The monomeric LHCB are proposed to play a pivotal role in protection of PSII by regulating energy 154 flow from the peripheral antenna system to the core subunits (De Bianchi et al. 2011). The minor 155 light-harvesting complexes such as LHCB4 located between the reaction center of photosystem Il and 156 the LHC trimers (Caffarri et al. 2014), were proposed to play a pivotal role in protection of the 157 photosystem by regulating energy flow from the peripheral antenna system to the reactions centers (De 158 Bianchi et al. 2011). CP29 is reversibly phophorylated in high light. Hence, a decline in the abundance 159 of LHCB4 during exposure to high irradiance may serve in prevention of photo-oxidative damage of 160 PSII (Humbeck and Krupinska 2003). These studies reveal that reorganization of LHC is involved in 161 the modulation of senescence in response to changes in the light intensity in barley. In several mutant plants the stay-green character of the plants positively correlates with the 163 retained chlorophyll $b$ content, implying an important role of the degradation of LHC for the initiation 164 of senescence. The construction and destruction of LHC is regulated by three enzymes of the chlorophyll cycle, i.e. chlorophyll $a$ oxygenase, chlorophyll $b$ reductase and 7-hydroxymethyl 166 chlorophyll reductase (Tanaka and Tanaka 2011). When the chlorophyll $a / b$ ratio in plants is lowered 167 by overexpression of chlorophyll $a$ oxidase or its catalytic domains only, chlorophyll $b$ was incorporated into the core complexes of the photosystems (Hirashima et al. 2006) with a stay-green 169 phenotype both in light and in darkness (Sakuraba et al. 2012b). Additionally, Kusaba et al. (2007) 170 found that the rice mutant defective in the gene for a chlorophyll $b$ reductase (NYCl) retained LHCII and grana during senescence. In the mutant of Arabidopsis thaliana impaired in NYCl gene in the

172 stay-green phenotype occurs not only during senescence in the light but also in the dark as is the case 173 in the chlorophyll $a$ oxygenase overexpressing plants (Jibran et al. 2015). From these studies, it has 174 been discussed that excessive chlorophyll $b$ leads to activation of a signaling pathway connecting the 175 chloroplast status and the nuclear gene expression (Sakuraba et al. 2012b). A much more likely 176 explanation for the stay-green phenotype is the stabilization of the photosystems by exchange of 177 chlorophyll $a$ by chlorophyll $b$ within originally only chlorophyll $a$ binding pigment protein 178 complexes such as CP43, CP47 and PSI reaction centre (Hirashima et al. 2006; Sakuraba et al. 2010). 
179 This may be explained by the fact that detachment of chlorophyll $b$ from the protein requires more 180 energy than detachment of chlorophyll $a$ (Horn et al. 2007). Finally, Voitsekhovskaja and Tyutereva 181 (2015) proposed in their review that stabilization of pigment protein complexes by chlorophyll $b$ can 182 change the level of signaling molecules necessary for senescence induction.

183 Gregersen et al. (2013) proposed that the light-dependent degradation of the minor LHC 184 (Humbeck and Krupinska 2003) is related to enhanced synthesis of abscisic acid known to accelerate the senescence process (Gepstein and Thimann 1980). Indeed, neoxanthin can dissociate from LHCII upon temperature increase providing a substrate pool for synthesis of abscisic acid as part of a heat and a drought response (Hobe et al. 2006). Further, the minor LHCs bind a high amount of the xanthophylls that can be utilized as substrates for biosynthesis of abscisic acid (Seo and Koshiba 2011;

189 Caffarri et al. 2014). It is hence possible that the synthesis of abscisic acid as result of degradation processes in the antenna system could be a specific mechanism for retrograde control of nuclear gene expression by plastids being degraded during senescence as reported by Pfannschmidt and Munné-

192 Bosch (2013). Intriguingly, plants overexpressing LHC genes showed enhanced stomata 193 responsiveness to abscisic acid and drought resistance, while disruption of any apoprotein of LHC in Arabidopsis thaliana was observed to increase drought sensitivity of the mutants (Xu et al. 2012). Accordingly, chlorophyll $b$ less mutants were reported to be less resistant towards drought (Voitsekhovskaja and Tyutereva 2015) pinpointing to common features in stress response and senescence.

\section{2.c Degradation of photosystems}

Many studies show preferential loss of either PSI or PSII or of both in parallel during leaf senescence. A unique strategy of adjustment of the photosystems to the electron transport capacity seems not to exist. The different strategies observed may depend on the nitrogen status or on the environmental conditions before and during the onset of senescence. No systematic differences between monocotyledons and dicotyledons were reported. Further, the difference between the stability of PSII compared to PSI seems to genetically depend on species and varieties. An early loss of PSI activity compared to PSII activity was observed in barley, cv. Steffi (Miersch et al. 2000), in rice, cv. IIyou 129 and Shangyou 63 (Tang et al. 2005), in oak (Quercus bicolor Wild.) and in sugar maple (Acer saccharum Marsh.; Moy et al. 2015), while a high stability of PSI was found in Festuca pratensis, cv. Rossa (Hilditch et al. 1989), in rice, cv. Nipponbare (Yamazaki et al. 1999), in 
211 (Schöttler et al. 2017). Krupinska et al. (2012) reported for two different varieties of barley grown in 212 the same year in the field differences in the stability of PSII compared to PSI and in changes of the 213 chloroplast ultrastructure during chloroplast to gerontoplast transition. In flag leaves of cv. Lomerit 214 PSII activity declined earlier than PSI activity while in cv. Carina the opposite was observed (Krieger215 Liszkay et al. 2015). In cv. Lomerit the level of LHCII proteins declined very early upon the onset of senescence and grana stacks were reduced which is in accordance with an early degradation of LHCII and PSII. In contrast to cv. Lomerit cv. Carina showed the typical structure of gerontoplasts with loosened grana stacks and with reduced interconnecting stroma thylakoids (Mulisch and Krupinska 2013). This goes hand in hand with an early loss of stroma thylakoids compared to grana stacks during senescence (Krupinska et al. 2012). This indicates that differences in the stability of the photosynthetic complexes during senescence can vary within one species (Krieger-Liszkay et al. 2015). It is an open question whether these differences are in general genetically determined, as it seems to be the case at first glance in the two barley varieties, or whether preferential degradation of PSII compared to PSI or vice versa depends on environmental factors like light intensity and quality (UV dose), temperature or nitrogen availability. With barley plants grown in the field it has been shown that the level of the D1 protein declines before Cyt $b_{6} f$ complex (Humbeck et al. 1996). This is most likely a consequence of the high light intensity and UV plants are exposed to in the field. However, in a controlled environment with maximal irradiance of $350 \mu \mathrm{mol} \mathrm{m} \mathrm{m}^{-2}$ the D1 protein was more stable than the rapidly declining FNR (Kucharewicz et al. 2017) catalyzing the transfer of electrons from PSI to the terminal acceptor $\mathrm{NADP}^{+}$of the electron transport chain.

Possibly, the net loss of PSII during senescence is just the accumulation of oxidative damage to a degree that the repair system cannot take care any longer about it. It is well known that after photo-oxidative damage to PSII, i.e. PSII photoinhibition, the core subunit D1 protein is fast degraded by Deg and FtsH proteases and fast resynthesized. The half-time in the light of the D1 protein was estimated to be $2.5 \mathrm{~h}$ (Nelson et al. 2014; Li et al. 2017). The D1 resynthesis and the repair of PSII in the so-called damage-repair cycle (Aro et al. 1993) are very efficient so that no net loss of D1/PSII is seen over a wide range of light intensities in mature plant leaves (Edelman and Mattoo, 2008). Contrary, the susceptibility of PSII to photo-oxidative damage was shown to increase with senescence in detached leaves of rye (Secale cereal L. cv. Halo), owing to a decline of the repair capacity of PSII 240 (Kar et al. 1993). Wang et al. (2016) proposed that both degradation and resynthesis of the D1 protein are declined during senescence in flag leaves of rice, cv. Zhehui7954. Increased vulnerability to photoinhibition has also been attributed to an imbalance in the photosynthetic apparatus caused by 
243 differential rates of decline during senescence, e.g. the decreases in Cyt $b_{6} f$ complex, plastocyanin and

244 Rubisco as described below, resulting in a greater capacity for light capture than required for carbon 245 reduction (Hodgkinson 1974; Allahverdiyeva et al. 2005).

\section{2.d Decrease in Cyt $b_{6} f$ complex and plastocyanin}

In respect to the photosynthetic electron transport chain, it has been reported that in tobacco Cyt $b_{6} f$ complex is the first protein complex that is degraded which leads to a decrease of the activity of photosynthetic linear electron flow (Ben-David et al. 1983; Roberts et al. 1987; Schöttler and Tóth 2014; Schöttler et al. 2017). Similar early loss of Cyt $b_{6} f$ complex together with a loss of the chloroplast ATP synthase has been observed in rice, cv. Sasanishiki (Hidema et al. 1991). Under optimal conditions in mature chloroplasts, Cyt $b_{6} f$ complex is the rate determining step of the linear electron transport chain. A reduction in the amount of this complex relative to the photosystems exerts a control effect on photosynthetic electron transport. A loss or a reduction in the amount of Cyt $b_{6} f$ complex compared to PSII and/or PSI reduces linear electron flow. Not only linear flow but also cyclic electron flow around PSI can depend also on Cyt $b_{6} f$ complex. However, cyclic electron flow may require a supercomplex formation of Cyt $b_{6} f$ complex with PSI, LHCI, LHCII, FNR and proton gradient regulation 5-like 1 protein (PGRL1; Iwai et al. 2010) or with PSI and NDH complex (Yadav et al. 2017; Kato et al. 2018). The proportion of PSI involved in these complexes is minor compared to PSI participating in linear electron flow. Thus, a reduction in the ratio Cyt $b_{6} f /$ PSI may not affect these supercomplexes but mainly linear electron flow.

In addition to a decrease in the level of Cyt $b_{6} f$ complex a decrease in the level of plastocyanin has been observed upon onset of senescence and electron transport in tobacco, cv. Samsun NN (Schöttler et al. 2014; 2017). In senescing tobacco leaves plastocyanin reduction by Cyt $f$ is delayed and the equilibration between plastocyanin and $\mathrm{Cyt} f$ is disturbed. Reoxidation of $\mathrm{Cyt} f$ by plastocyanin limits under these conditions electron flow and not, like in non-senescent leaves, the plastoquinoloxidase activity of Cyt $b_{6} f$ complex (Schöttler et al. 2004). A correlation between plastocyanin content and electron transport rate has also been reported for barley (Burkey 1994). In Arabidopsis thaliana, however, $90 \%$ decrease in plastocyanin content did not limit electron flow under conditions of nonsenescent plants grown under standard conditions (Pesaresi et al. 2009). However, when different

272 developmental stages were tested, the mutant pete2-1 that contains drastically less plastocyanin 273 (Pesaresi et al. 2009) showed the highest peak in chlorophyll content three days earlier than the corresponding wild type, indicative of an earlier senescence start (Wang et al. 2015). Although less 
intensively studied as Cyt $b_{6} f$ complex, changes in plastocyanin content and reduction kinetics may be the key element that controls a decrease of linear electron flow upon onset of senescence. The other diffusible electron carrier, plastoquinone that shuttles electrons between PSII and Cyt $b_{6} f$ complex, does not change in content during senescence (Schöttler et al. 2004). If plastocyanin/Cyt $b_{6} f$ control the photosynthetic electron transport rate, the content of PSII and PSI are possibly adjusted to the maximal capacity of electron transport during senescence, or alternatively an excess of photosystems might serve for specific electron pathways or for signaling events.

Isotopic labelling coupled with mass spectrometry analyses has enabled the determination of degradation rates and half-lives of hundreds of individual proteins ( $\mathrm{Li}$ et al. 2017; Li et al. 2018), indicating that the subunit PetD of Cyt $b_{6} f$ complex shows a comparably high degradation rate as the D1 protein while the other subunits of the photosynthetic protein/pigment complexes were more stable. If the synthesis rate of the PetD protein is low in senescing leaves, this could explain the overall loss of Cyt $b_{6} f$ complex upon the initiation of senescence. Altogether more than 20 different proteases have been discovered that degrade chloroplast proteins, some of which are associated with senescence (Gepstein et al. 2003; Martínez et al. 2008; for a recent review see Nishimura et al. 2016). It has been suggested that $\mathrm{ClpP}$ protease functions in the degradation of chloroplast proteins, including Cyt $b_{6} f$ complex (Majeran et al. 2000). However, the amount of the ClpP transcript decreases with leaf senescence in field-grown barley, cv. Trixi (Humbeck and Krupinska 1996), indicating that the degradation of the PetD protein during senescence is independent on the ClpP-dependent protein degradation. Overall, the mechanism of the decline of Cyt $b_{6} f$ complex is still unclear.

\section{2.e Alternative electron transport pathways in gerontoplasts}

When, upon the onset of senescence, the capacity of linear electron transport decreases because of a reduction of plastocyanin, Cyt $b_{6} f$ content and changes in the electron transport between plastocyanin and Cyt $b_{6} f$ complex, alternative electron pathways may become more important, for example in gerontoplast in senescing leaves, than it is the case in mature leaves (Fig. 2). The reorganization of the thylakoid membrane system and the export of nitrogen, carbon, metals etc. from chloroplasts to sink tissue is a highly energy demanding process requiring ATP. ATP in chloroplasts with a disrupted linear electron transport chain can be generated via cyclic electron flow or via chlororespiratory pathways. Cyclic electron flow may persist if the fraction of Cyt $b_{6} f$ complex and plastocyanin involved in supercomplex formation is less degraded during senescence than the main fraction participating in linear electron flow. Plants that keep PSI until a late stage of development 
may profit from cyclic electron flow to generate ATP. Plants that lose PSI during early stages of senescence may rely more on chlororespiratory electron flow via the NDH complex and plastid terminal oxidase (PTOX). In non-green plastids electron transport generating a proton motif force and ATP has been described. In chromoplasts isolated from tomato (Solanum lycopersicum cv. MicroTom; Renato et al. 2014), generation of a proton motif force by electron transport involving the NDH complex, plastoquinone and PTOX has been shown to take place. The same is the case in etioplasts (Kambakam et al. 2016). However, to be efficient, the levels of NDH and PTOX, both minor compounds of the thylakoid membrane in mature chloroplasts (Lennon et al. 2003), have to be significantly increased upon the start of senescence. Indeed, the amount and activity of the NDH complex was observed to increase during senescence in tobacco, cv. Petit Havana (Zapata et al. 2005). Additionally, larger amounts of NDH and PTOX have been detected in senescent leaves than in mature leaves of oat (Avena sativa L., cv. Prevision; Tallón and Quiles 2007). Furthermore, hydrogen peroxide $\left(\mathrm{H}_{2} \mathrm{O}_{2}\right)$, a ROS generated upon the onset of senescence, can activate the NDH-dependent cyclic flow and render enzymes of the Calvin-Benson cycle inactive (Strand et al. 2015).

\section{2.f Loss of Rubisco}

Alteration of photosynthesis during senescence depends not only on the photosynthetic electron transport but also on the Calvin-Benson cycle. Rubisco, the enzyme initiating photosynthetic $\mathrm{CO}_{2}$ assimilation and photorespiration, is also one of the important photosynthetic components degraded during leaf senescence. Approximately half of the nitrogen in chloroplasts is occupied by Rubisco (Hörtensteiner and Feller 2002), showing that Rubisco degradation plays a large role for the remobilization of nitrogen. Senescing leaves of the $C_{3}$ plant rice (cv. Sasanishiki) showed an earlier degradation of Rubisco than of chlorophyll at the early stage of senescence (Hidema et al. 1991). However, the degradation of Rubisco has often been reported to be slower than that of photosynthetic electron transport components, including PSII, PSI, and Cyt $b_{6} f$ (see for example Krupinska et al. 2012). However, during natural senescence in Arabidopsis thaliana leaves, a decrease in Rubisco is observed along with rapid decreases in PSII and Cyt $f$ (Nath et al. 2013). A decrease in Rubisco during senescence limits photosynthetic activity under high light. In low light and/or low available nitrogen, where low levels of Rubisco are required to maintain a maximal assimilation rate, Rubisco is degraded as fast as Cyt $f$ in Morning glory (Ipomoea tricolor Cav. cv. Heavenly Blue; Hikosaka 1996). The affinity of Rubisco for $\mathrm{CO}_{2}$ and $\mathrm{O}_{2}$, respectively, may also vary during senescence. A decrease in 
sunflower (Helianthus annuus L. cv. Spanners Allzweck; Betsche and Eising 1989), but there is little

340 report on the role of photorespiration in leaf senescence.

Rubisco is digested by specialized autophagic bodies and even whole chloroplasts can be digested by autophagy (Ishida et al. 2014). Rubisco alone accounts for about 50\% of total soluble proteins in the leaf nitrogen in $\mathrm{C}_{3}$ plants. Autophagy is induced by energy limitation due to interruption of photosynthetic carbon fixation. Inhibition of photosynthetic electron transport by DCMU, a herbicide which binds to the acceptor side of photosystem II and blocks linear electron transport, stimulates the initiation of autophagy (Izumi et al. 2015; for recent reviews on autophagy see Havé et al. 2017; Izumi and Nakamura 2018). Photoinhibition by visible or UV light also induces autophagy (Izumi and Nakamura 2017), suggesting strongly that an impairment of the photosynthetic electron transport chain and concomitant ROS production are triggers for autophagy initiation and extra plastidic degradation pathways such as the ubiquitin-proteasome system (Ling et al. 2012; Woodson 2016).

On the other hand, it has been shown that the cysteine protease targeted to plastids is involved in the degradation of Rubisco during senescence. Compelling evidence for chloroplast degradation by plastid protease is the observation that isolated chloroplasts kept in the light accumulate a $44 \mathrm{kDa}$ cleavage product of the large subunit of Rubisco (Feller et al. 2008a, b). In barley HvPAP14 encoding a cysteine protease is highly expressed during senescence (Hollmann et al. 2014). The cysteine protease HvPAP14 is targeted to chloroplasts where it is in association with the thylakoid membrane, and thus can be activated by low $\mathrm{pH}$ of the lumen. Additionally, the overexpression mutant of HvPAP14 accumulates specific degradation products of the large subunit of Rubisco (Frank et al. 2018, submitted to the Plant Journal). Many cysteine proteases associated with senescence are predicted to be synthesized at the endoplasmic reticulum and to be active in the vacuole (Callis 1995). Searches for senescence associated proteases revealed that only few of them are targeted to plastids (Gepstein et al. 2003). Hence, final degradation of chloroplast proteins, including Rubisco, is likely occurring in the vacuolar compartment (Feller et al. 2008a; Martínez et al. 2008).

\section{Generation of reactive oxygen species in chloroplasts upon initiation of senescence}

It has been recognized since many years that plant leaves during senescence have increased ROS levels, in particular $\mathrm{H}_{2} \mathrm{O}_{2}$ (Dhindsa et al. 1981; Kar and Feierabend 1984), and it has been proposed that ROS are involved in the initiation of senescence (for reviews Zimmermann and Zentgraf 2005; Juvany et al. 2013). Indeed, many genes upregulated during senescence are also upregulated in 
response to $\mathrm{H}_{2} \mathrm{O}_{2}$ (Sabater and Martín 2013). Increased levels of ROS during senescence have been reported to coincide with enhanced lipid peroxidation in chloroplasts (Dhindsa et al. 1982; Hopkins et al. 2007) and oxidized proteins (Mehta et al. 1992; Vanacker et al. 2006). Furthermore, singlet oxygen $\left({ }^{1} \mathrm{O}_{2}\right)$ has been shown to induce autophagy and extra plastid degradation pathways involving the ubiquitin/E3 ligase system (Ling et al. 2012; Woodson 2016).

Although there is no doubt about the involvement of ROS in initiation and execution of senescence, the cellular sources of the senescence associated ROS are hitherto not known, except for the clear evidence for $\mathrm{H}_{2} \mathrm{O}_{2}$ production in peroxisomes (Pastori and del Rio 1997). During senescence the photosynthetic electron transport chain altering as described above might become another major source for ROS such as singlet oxygen $\left({ }^{1} \mathrm{O}_{2}\right)$, superoxide anion radicals $\left(\mathrm{O}_{2}{ }^{\bullet-}\right)$ and also $\mathrm{H}_{2} \mathrm{O}_{2}$ (Apel and Hirt 2004; Dietz et al. 2016). The exact site and mechanism of ROS production in senescing chloroplasts has, however, not been identified so far at the molecular level.

\section{3.a Singlet oxygen $\left({ }^{1} \mathrm{O}_{2}\right)$}

When excited chlorophyll in its triplet state $\left({ }^{3} \mathrm{Chl}\right)$ reacts with molecular oxygen $\left({ }^{3} \mathrm{O}_{2}\right){ }^{1} \mathrm{O}_{2}$ is generated. The triplet state of chlorophyll is generated by charge recombination reactions in the PSII reaction centre (for review see Rutherford and Krieger-Liszkay, 2001; Krieger-Liszkay 2005) and in LHCII when it is damaged (Rinalducci et al. 2004; for review see Fischer et al. 2013), and probably also when it starts to be degraded during senescence. In the functional intact LHCII the formation of the triplet state of chlorophyll is avoided by the close distance between carotenoid and chlorophyll molecules (Edge and Truscott 2010).

Experiments on two barley varieties, cv. Carina and cv. Lomerit, revealed that these two varieties employ different strategies of senescence in respect to ROS generation in plastids (KriegerLiszkay et al. 2015). Lomerit showed an early loss of PSII activity and LHCII (Krupinska et al. 2012) and an increase in both, ${ }^{1} \mathrm{O}_{2}$ and $\mathrm{O}_{2}{ }^{-}$during senescence while Carina showed an early loss of PSI activity compared to PSII, a similar increase in $\mathrm{O}_{2}{ }^{\bullet-}$ like Lomerit but, different to Lomerit, a constant low level of ${ }^{1} \mathrm{O}_{2}$ production. No increase in ${ }^{1} \mathrm{O}_{2}$ generation in Carina together with a high stability of PSII and LHCII indicate that in Lomerit either degradation of PSII or LHCII are responsible for the observed increase in ${ }^{1} \mathrm{O}_{2}$. When forward electron transport is blocked, due to the decrease in Cyt $b_{6} f$ complex and plastocyanin, charge recombination reactions in PSII are favored and the probability of charge recombination reactions leading to the formation of the triplet state of the reaction center 
such as CP29 (Humbeck and Krupinska 2003) and LHCII may also increase ${ }^{1} \mathrm{O}_{2}$ generation when the close distance between chlorophyll and neighboring carotenoids is not any longer conserved or when free chlorophyll or chlorophyll breakdown products accumulate which act as photosensitizers.

The ${ }^{1} \mathrm{O}_{2}$ amount can be modulated by the level of carotenoids quenching ${ }^{1} \mathrm{O}_{2} .{ }^{1} \mathrm{O}_{2}$ can be scavenged also by $\alpha$-tocopherol that is re-reduced by ascorbate. As shown in a previous study with pea, a decline in the ascorbate pool is a good marker of the onset of leaf senescence (Vanacker et al. 2006). The contents of carotenoids are suggested to be usually stable relative to those of chlorophyll during leaf senescence (Yoo et al. 2003). Lutein, $\beta$-carotene, and xanthophyll cycle pigments: i.e. violaxanthin, antheraxanthin, and zeaxanthin decline, whereas the amount of $\alpha$-tocopherol is increased during leaf senescence of wheat (Hordeum vulgare L. cv. Dyan; Afitlhile et al. 1993), pea (Pisum sativum L. cv. Phoenix; Dertinger et al. 2003), in field-grown Salvia officinalis L. (Elizabeth and Sergi 2007) and $\alpha$ - and $\gamma$-tocopherol in tobacco (Falk et al. 2003). Therefore, tocopherol becomes an important antioxidant in senescing leaves. These alterations may be important for the initiation of senescence through the modulation of ROS concentrations.

\section{3.b Superoxide anion radical $\left(\mathrm{O}_{2}{ }^{\bullet-}\right)$ and hydrogen peroxide $\left(\mathrm{H}_{2} \mathrm{O}_{2}\right)$}

Both $\mathrm{O}_{2}{ }^{\bullet-}$ and $\mathrm{H}_{2} \mathrm{O}_{2}$ can be generated by the reduction of $\mathrm{O}_{2}$ in photosynthetic electron transport in a number of different reactions. First, $\mathrm{O}_{2}$ can act as a terminal electron acceptor in the Mehler reaction at the acceptor side of PSI (Asada et al. 1974). Second, it can be reduced also by semiplastoquinones in the thylakoid membrane (Mubarakshina and Ivanov 2010). Third, $\mathrm{O}_{2}$ can be reduced to $\mathrm{O}_{2}{ }^{\bullet-}$ at the acceptor side of PSII (Pospíšil et al. 2004). During photosynthetic linear electron flow these reductions of $\mathrm{O}_{2}$ to $\mathrm{O}_{2}{ }^{\bullet-}$ can occur under conditions of limited electron acceptor availability other than $\mathrm{O}_{2}$. Finally, alternative electron transport may also be involved in the productions of $\mathrm{O}_{2}{ }^{\bullet-}$ and $\mathrm{H}_{2} \mathrm{O}_{2}$. A mutant of tobacco (cv. Petit Havana) lacking NDH complex, that is homologous to complex I in mitochondria, was shown to have retarded senescence (Zapata et al. 2005), and it has been suggested that NDH complex, is responsible for increased $\mathrm{O}_{2}{ }^{\bullet-}$ and $\mathrm{H}_{2} \mathrm{O}_{2}$ production during senescence. In mitochondria, indeed complex I besides complex III is regarded as the main source of these ROS (Chen et al. 2003; Murphy 2009). PTOX can also generate $\mathrm{O}_{2}{ }^{\bullet-}$ in a side reaction depending on substrate availability (Yu et al. 2014) although this enzyme catalyzes as main reaction the reduction of $\mathrm{O}_{2}$ directly to $\mathrm{H}_{2} \mathrm{O}$. Two molecules of $\mathrm{O}_{2}{ }^{\circ-}$ are converted to $\mathrm{H}_{2} \mathrm{O}_{2}$ and $\mathrm{O}_{2}$ in disproportionation, either spontaneously or catalyzed by superoxide dismutase (SOD). In the presence of reduced transition metal ions such as $\mathrm{Fe}^{2+}, \mathrm{H}_{2} \mathrm{O}_{2}$ gives rise to the highly reactive hydroxyl radical 
$435\left(\mathrm{HO}^{\bullet}\right)$ supported by the reduction of $\mathrm{Fe}^{3+}$ by $\mathrm{O}_{2}{ }^{-}$(Haber-Weiss reaction). Upon the initiation of 436 senescence linear electron transport declines (see above) and therefore also the production of ROS as 437 byproduct of photosynthetic electron transport is expected to decline. This has been shown to be the 438 case for the generation of $\mathrm{O}_{2}{ }^{\bullet-}$ and $\mathrm{H}_{2} \mathrm{O}_{2}$ in thylakoids isolated from barley, cv. Golden Promise, while, 439 however, the level of lipid peroxidation products, mainly generated by ROS, increased during senescence (Jajić et al. 2015). Furthermore, during senescence the capacity of $\mathrm{O}_{2}{ }^{\bullet-}$ production was 441 shown to increase in thylakoid membranes isolated from flag leaves of field-grown barley (cv. 442 Lomerit and cv. Carina; Krieger-Liszkay et al. 2015). In leaves of Arabidopsis thaliana, $\mathrm{H}_{2} \mathrm{O}_{2}$ levels 443 have also been shown to increase with the initiation of senescence and this increase correlated with a 444 loss of CAT2, the main isoform of catalase in leaves, localized in peroxisomes and ascorbate 445 peroxidase activity (Zimmermann et al. 2006). These facts suggest that the generation of $\mathrm{O}_{2}{ }^{\bullet-}$ and $446 \mathrm{H}_{2} \mathrm{O}_{2}$ in chloroplasts during senescence is affected also by the alterations of the scavenging systems.

447 Alteration of ROS-scavenging enzymes can be observed during leaf senescence, often 448 combined with those of the photosynthetic apparatus and the generation of $\mathrm{O}_{2}{ }^{\bullet-}$ and $\mathrm{H}_{2} \mathrm{O}_{2}$. In 449 chloroplasts, $\mathrm{O}_{2}{ }^{\bullet}$ is rapidly dismutated by SOD into $\mathrm{H}_{2} \mathrm{O}_{2}$ which is itself detoxified, in chloroplasts, by 450 peroxidases such as ascorbate peroxidase from the ascorbate-glutathione cycle (Noctor and Foyer 451 1998). In this cycle, oxidized ascorbate and glutathione are re-reduced by enzymes using NADPH as 452 cofactor. Therefore, the regeneration of these cofactors is coupled with photosynthetic electron 453 transport (Miyake and Asada 1992). Other peroxidases, such as peroxiredoxins such as 2 Cys-Prx and 454 Prx-Q are important in chloroplast ROS detoxification (Dietz 2011). In the $\mathrm{C}_{3}$ plants tobacco 455 (Nicotiana tabacum L. cv. Samsun) and pea (Pisum sativum L. cv. Phoenix) the amounts of ascorbate 456 and glutathione decrease during leaf senescence, and thereafter the activities of ascorbate peroxidase 457 and glutathione reductase declined with a little retardation (Dertinger et al. 2003; Vanacker et al. 458 2006). Other antioxidative enzymes, including SOD, catalase, dehydroascorbate reductase, and 459 monodehydroascorbate reductase also decrease with leaf senescence (Dertinger et al. 2003; Vanacker 460 et al. 2006), indicating that antioxidative systems totally decline during leaf senescence. The induction 461 of SOD gene expression in response to stress becomes progressively impaired when leaves enter 462 senescence (Casano et al. 1994; Kurepa et al. 1997; Ohe et al. 2005; Procházková and Wilhelmová 463 2007). Interestingly, Vanacker et al. (2006) showed the transient increase in these enzyme activities at 464 the early stage of senescence, which possibly regulates the ROS level in the cells. This may play a role 465 to retard senescence and to prolong the lifespan of the cell. On the other hand, it should be also noted 
that the changing capacities of these ROS-scavenging enzymes with increasing age has been suggested not to be the cause but a consequence of leaf senescence in plants (Dertinger et al. 2003).

\section{Retrograde signalling in the control of senescence}

Photosynthetic activity is highly susceptible to environmental cues such as irradiance, temperature and water supply and this feature makes chloroplasts excellent sensors of environmental information. Moreover, chloroplasts permanently transmit information about the functional state of the photosynthetic apparatus to the nucleus by various signalling molecules/factors, such as ROS, carotenoid-derived oxidation products with signalling function (Ramel et al. 2012; Shumbe et al. 2017), and hormones synthesized in chloroplasts (Bouvier et al. 2009). Responses in the nucleus ensure that plants acclimate to the changing environmental situation and avoid oxidative stress (operational control) (Pogson et al. 2008). To ensure a coordinate dismantling of chloroplasts during senescence and thereby an efficient remobilization of the nutrients, retrograde signalling has been proposed to be also of importance also during this phase of development (degradational control) (Pfannschmidt and Munné-Bosch 2013).

The decline in photosynthetic activity during senescence likely results in an excess light situation in the dismantling chloroplasts, i.e. light is in excess for the remaining photosynthetic units diminishing in number during senescence. In order to allow for a controlled and efficient remobilization of nutrients from chloroplasts it is important that the remaining photosynthetic units work efficiently and oxidative stress is prevented. Indeed, even in the field the decline in Fv/Fm occurs much later than the declines in photosynthetic gas exchange and chlorophyll content indicating that the residual photosynthetic units still work efficiently (Humbeck et al. 1996, Krupinska et al. 2012). This indicates that for a certain time plants are capable to cope with the excess energy situation resulting from the dismantling of the photosynthetic apparatus. It is well-known that SAbeing produced by chloroplasts is responsible for the plants' acclimation to high light by altering gene expression in the nucleus (Szechynska-Hebda and Karpinski 2013). It is hence likely that SA involved in retrograde signaling from chloroplasts is also important during senescence. ROS generated during disassembly of the photosynthetic apparatus may be implicated in changes of the hormone status during senescence. efficient remobilization of nutrients from the senescing leaves to other still growing leaves and to seeds (Juvany et al. 2013), ROS are also required as signals for induction of stress responses, development and senescence (Apel and Hirt 2004; Li et al. 2009; Foyer and Noctor 2013; Dietz et al. 
2018). Different ROS, such as ${ }^{1} \mathrm{O}_{2}$ and $\mathrm{O}_{2}{ }^{\bullet} / \mathrm{H}_{2} \mathrm{O}_{2}$ induce different signalling cascades. ${ }^{1} \mathrm{O}_{2}$ is not only a very potent oxidant leading to oxidative damage of nucleic acids, lipids and proteins but it is also triggering a signalling pathway distinct from $\mathrm{O}_{2}{ }^{\bullet-} / \mathrm{H}_{2} \mathrm{O}_{2}$ mediated signaling (Galvez-Valdivieso and Mullineaux 2010; Fischer et al. 2013; Laloi et al. 2007; Laloi and Havaux 2015). Senescence associated declines in the levels of antioxidative systems have been reported and could be crucial for ROS dependent initiation of senescence (Procházková and Wilhelmová 2007). Throughout senescence ROS, especially $\mathrm{H}_{2} \mathrm{O}_{2}$, are believed to play a pivotal role in signalling and molecule degradation (Zentgraf et al. 2012). Many senescence-associated TFs are highly responsive to $\mathrm{H}_{2} \mathrm{O}_{2}$ in Arabidopsis thaliana including, for example, WRKY53 (Miao et al. 2004), ORS1 (Balazadeh et al. 2011), JUB1 (Wu et al. 2012) and ATAF1 (Garapati et al. 2015). Efficient signal transduction by ROS requires that the levels of ROS are kept under a tight control that is governed by enzymatic and non-enzymatic ROS-scavenging systems.

SA besides JA and ABA, accumulates during natural senescence (Morris et al. 2000) and is involved in the control of a large set of nuclear genes upregulated during senescence (Morris et al. 2000; Buchanan-Wollaston et al. 2005). Comparing gene expression during natural/developmental senescence and dark/starvation induced senescence revealed that SA is involved in control of natural senescence in the light rather than in the regulation of dark-induced senescence (Buchanan-Wollaston et al. 2005). A subset of the SA-dependent senescence associated genes is also expressed during pathogen responses (PR) and cell death (Buchanan-Wollaston et al. 2005). Since a higher SA content has been also measured in plants after treatment with UV-C radiation (Yalpani et al. 1994) it is likely that SA is of utmost importance for senescence and plant productivity under field conditions.

The DNA binding protein WHIRLY1 which is located in both chloroplasts and nucleus of the same cell is an interesting candidate for transducing signals from chloroplasts to the nucleus (Grabowski et al. 2008). It had been first identified as a transcription factor inducing expression of PR genes in a salicylic acid dependent manner (Desveaux et al. 2004) making it an ideal candidate for retrograde signaling during senescence. Barley plants with an RNAi mediated WHIRLY1 knockdown are compromised in responding to environmental changes due to a reduced capability to synthesize microRNAs (Swida-Barteczka et al. 2018). When exposed to high irradiance the WHIRLY1 deficient plants show retarded senescence in comparison to the wild type that is able to accelerate senescence processes in response to environmental cues such as high light (Kucharewicz et al. 2017). Interestingly, the level of salicylic acid is higher in the WHIRLY1 deficient plants than in the wild type (Kucharewicz et al. 2017) clearly indicating that WHIRLY1 acts downstream of salicylic acid. It 
530 has been proposed that SA induces a conformational change of oligomeric WHIRLY1 yielding 531 monomeric WHIRLY1 that is able to translocate from chloroplasts to the nucleus (Foyer et al. 2014).

532 In the WHIRLY1 deficient plants retarded senescence was shown to coincide with a reduced thousand 533 grain weight (Kucharewicz and Krupinska, unpublished data) indicating that an appropriate reaction to 534 the environment is important for the senescence associated nutrient remobilization and productivity of crop plants. Interestingly, the WHIRLY1 deficient plants are not affected in dark-induced senescence (Kucharewicz et al. 2017) underpinning the importance of the photosynthetic apparatus in determining onset and progression of senescence under natural conditions.

\section{Conclusions and Perspectives}

540 In recent years leaf senescence has been mainly investigated in the model plant Arabidopsis thaliana under controlled environmental conditons including darkness as a tool for induction of senescence.

542 Considering that leaf senescence is of high importance for crop yields, there is an urgent need for more 543 studies with various crop plants in the field (Gregersen et al. 2013) or under controlled growth 544 conditions allowing the simulation of real climate conditions (temperature, irradiance, humidity) 545 (Franzaring et al. 2011). Characterization of leaf senescence under field conditions revealed that the 546 sequence of events leading to the dismantling of the photosynthetic apparatus differs from that under 547 controlled conditions in growth chambers (e.g. D1 degradation). Relevant senescence modifying 548 factors identified in the field should be furthermore systematically tested under controlled climatic, 549 soil and plant canopy conditions. These studies should monitor both senescence associated changes in 550 the photosynthetic apparatus and in remobilization of nitrogen and other nutrients. Premature senescence due to adverse environmental situation is known to decrease crop productivity. Future studies should be conducted using different light intensities with varying proportions of UV as well as

553 fluctuating light in combination with a variety of temperatures to obtain results that are relevant for improvement of nutrient recycling and productivity of crop plants in the field.

In order to better control senescence associated processes with regard to an enhancement of 556 plant productivity, the relationship between photosynthesis originating ROS production and the production of senescence associated hormones by chloroplast metabolism needs to be elucidated.

558 Projects aiming to improve crop yields would have to include the objective to prolong the 559 photosynthetic/functional life span of the chloroplast without compromising recycling processes. 560 Comparative field studies on a few selected crop species should focus on the primary events in respect 561 to alterations of the photosynthetic apparatus to identify the key players (e.g. limiting step in electron 
562 transport, poising of the chloroplast redox state, activity of proteases) in controlling the lifespan of the 563 chloroplasts. Such studies will also permit to clarify which event(s) is/are indeed the primary factor/s 564 initiating leaf senescence and which photosynthetic reaction(s) would be needed to become improved 565 for enhancing crop yield. As described in the present review, the existing literature does neither allow 566 to identify a general senescence strategy (if existing) nor to elucidate the most important event/s 567 leading to an initiation of senescence.

\section{Acknowledgement}

A.K.L. and G.S. benefit from the support of the LabEx Saclay Plant Sciences-SPS (ANR-10-LABX0040-SPS) and the French Infrastructure for Integrated Structural Biology (FRISBI) ANR-10-INSB05. G.S. is supported by a JSPS oversea research fellowship (201860126). Research of K.K. is supported by the German Research Foundation (DFG, KR1350)

\section{References}

Afitlhile MM, Dent RM, Cowan AK (1993) Changes in carotenoid composition in senescing leaves of Hordeum vulgare L. cv. Dyan. J Plant Physiol 142: 43-49

Allahverdiyeva Y, Mamedov F, Maenpaa P, Vass I, Aro EM (2005) Modulation of photosynthetic electron transport in the absence of terminal electron acceptors: characterization of the $r b c L$ deletion mutant of tobacco. Biochim Biophys Acta 1709: 69-83

Allen JF (2003) Cyclic, pseudocyclic and noncyclic photophosphorylation: new links in the chain. Trends Plant Sci 8: 15-19

Apel K, Hirt H (2004) Reactive oxygen species: Metabolism, oxidative stress, and signal transduction. Annu Rev Plant Biol 55: 373-399

Aro EM, McCaffery S, Anderson JM (1993) Photoinhibition and D1 protein degradation in peas acclimated to different growth irradiances. Plant Physiol 103: 835-843

Asada K, Kiso K, Yoshikawa K (1974) Univalent reduction of molecular oxygen by spinach chloroplasts on illumination. J Biol Chem 249: 2175-2181

Balazadeh S, Kwasniewski M, Caldana C, Mehrnia M, Zanor MI, Xue G-P, Mueller-Roeber B (2011) ORS1, an $\mathrm{H}_{2} \mathrm{O}_{2}$-responsive NAC transcription factor, controls senescence in Arabidopsis thaliana. Mol Plant 4: 346-360 
Ben-David H, Nelson N, Gepstein S (1983) Differential changes in the amount of protein complexes in the chloroplast membrane during senescence of oat and bean leaves. Plant Physiol 73: 507510

Bennoun P (2005) The present model for chlororespiration, in Discoveries in Photosynthesis (Govindjee, Beatty JT, Gest H, Allen JF eds), Springer Netherlands, Dordrecht. p^pp 905-909

Betsche T, Eising R (1989) $\mathrm{CO}_{2}$-fixation, glycolate formation, and enzyme activities of photorespiration and photosynthesis during greening and senescence of sunflower cotyledons. J Exp Bot 40: 1037-1043

Bouvier F, Mialoundama AS, Camara B (2009) A sentinel role for plastids. In: Sandelius AS, Aronsson H (eds) The chloroplast. Springer, Heidelberg, pp 267-292

Buchanan-Wollaston V, Page T, Harrison E, Breeze E, Lim PO, Nam HG, Lin JF, Wu SH, Swidzinski J, Ishizaki K, Leaver CJ (2005) Comparative transcriptome analysis reveals significant differences in gene expression and signalling pathways between developmental and dark/starvation-induced senescence in Arabidopsis. Plant J 42: 567-585

Burkey KO (1994) Genetic variation of photosynthetic electron transport in barley: identification of plastocyanin as a potential limiting factor. Plant Sci 97: 177-187

Casano LM, Martin M, Sabater B (1994) Sensitivity of superoxide dismutase transcript levels and activities to oxidative stress is lower in mature-senescent than in young barley leaves. Plant Physiol 106: 1033-1039

Caffarri S, Tibiletti T, Jennings RC, Santabarbara S (2014) A comparison between photosystem I and photosystem II architecture and functioning. Curr Protein Peptide Science 15: 296-331

Callis J (1995) Regulation of protein degradation. Plant Cell 7: 845-857

Chen Q, Vazquez EJ, Moghaddas S, Hoppel CL, Lesnefsky EJ (2003) Production of reactive oxygen species by mitochondria: Central role of complex III. J Biol Chem 278: 36027-36031

De Bianchi, S, Betterle N, Kouril R, Cazzaniga S, Boekema E, Bassi R, Dall'Osto L (2011) Arabidopsis mutants deleted in the light-harvesting protein lhcb4 have a disrupted photosystem II macrostructure and are defective in photoprotection. Plant Cell 23: 2659-2679

Dertinger U, Schaz U, Schulze E-D (2003) Age-dependence of the antioxidative system in tobacco with enhanced glutathione reductase activity or senescence-induced production of cytokinins. Physiol Plant 119: 19-29 
A Whirly transcription factor is required for salicylic acid dependent disease resistance in Arabidopsis. Dev Cell 6: 229-240.

Dhindsa RS, Plumb-Dhindsa P, Thorpe TA (1981) Leaf senescence: Correlated with increased levels of membrane permeability and lipid peroxidation, and decreased levels of superoxide dismutase and catalase. J Exp Bot 32: 93-101

Dhindsa RS, Plumb-Dhindsa PL, Reid DM (1982) Leaf senescence and lipid peroxidation: Effects of some phytohormones, and scavengers of free radicals and singlet oxygen. Physiol Plant 56:

Dietz K-J (2011) Peroxiredoxins in plants and cyanobacteria. Antioxid Redox Signaling 15: 11291159

Dietz K-J, Turkan I, Krieger-Liszkay A (2016) Redox- and reactive oxygen species-dependent signaling into and out of the photosynthesizing chloroplast. Plant Physiol 171: 1541-1550

Dietz K-J, Wesemann C, Wegener M, Seidel T (2018) Towards an integrated understanding of retrograde control of photosynthesis. Antioxidants \& Redox Signaling (in press)

Edelman M, Mattoo AK (2008) D1-protein dynamics in photosystem II: the lingering enigma. Photosynth Res 98: 609-620

Edge R, Truscott T (2010) Properties of carotenoid radicals and excited states and their potential role in biological systems. CRC Press: Boca Raton, FL, USA

Elizabeth AM, Sergi MB (2007) Photo- and antioxidant protection and salicylic acid accumulation during post-anthesis leaf senescence in Salvia lanigera grown under Mediterranean climate. Physiol Plant 131: 590-598

Feller U, Anders I, Mae T (2008a) Rubiscolytics: fate of Rubisco after its enzymatic function in a cell

Falk J, Andersen G, Kernebeck B, Krupinska K (2003) Constitutive overexpression of barley 4is terminated. J Exp Bot 59: 1615-1624

Feller U, Anders I, Demirevska K (2008b) Degradation of rubisco and other chloroplast proteins under abiotic stress. Gen Appl Plant Physiol 34: 5-18 hydroxyphenylpyruvate dioxygenase in tobacco results in elevation of rge vitamin E content in seeds but not in leaves. FEBS Lett 540: 35-40

Fischer A, Feller U (1994) Senescence and protein degradation in leaf segments of young winter wheat: influence of leaf age. J Exp Bot 45: 103-109 
654 Fischer BB, Hideg E, Krieger-Liszkay A (2013) Production, detection, and signaling of singlet oxygen in photosynthetic organisms. Antioxid Redox Signaling 18: 2145-2162

Foyer CH, Karpinska B, Krupinska K (2014) The functions of WHIRLY1 and REDOXRESPONSIVE TRANSCRIPTION FACTOR 1 in cross tolerance responses in plants: a hypothesis. Phil Trans R Sco B 369

Foyer CH, Noctor G (2013) Redox Signaling in Plants. Antioxid Redox Signaling 18: 2087-2090

Fracheboud Y, Luquez V, Björkén L, Sjödin A, Tuominen H, Jansson S (2009) The control of autumn senescence in european aspen. Plant Physiol 149: 1982-1991

662

663

664

665

666

667

668

669

670

671

672

673

674

675

676

677

678

679

680

681

682

683

684

685

Franzaring J, Weller S, Schmid I, Fangmeier A (2011) Growth, senescece and water use efficiency of spring oilseed rape (Brassica napus L. cv. Mozart) grwon in a factorial combination of nitrogen supply and elevated $\mathrm{CO}_{2}$. Environ Exp Bot 72: 284-296

Galvez-Valdivieso G, Mullineaux PM (2010) The role of reactive oxygen species in signalling from chloroplasts to the nucleus. Physiol Plant 138: 430-439

Garapati P, Xue G-P, Munné-Bosch S, Balazadeh S (2015) Transcription factor ATAF1 in Arabidopsis promotes senescence by direct regulation of key chloroplast maintenance and senescence transcriptional cascades. Plant Physiol 168: 1122-1139

Gepstein S, Thimann KV (1980) Changes in the abscisic acid content of oat leaves during senescence. Proceed Nat Ac Sci USA 77: 2050-2053

Gepstein S, Sabehi G, Carp M-J, Hajouj T, Nesher MFO, Yariv I, Dor C, Bassani M (2003) Largescale identification of leaf senescence-associated genes. Plant J 36: 629-642

Grabowski E, Miao Y, Mulisch M, Krupinska K (2008) Single-stranded DNA binding protein Whirly1 in barley leaves is located in chloroplasts and nuclei of the same cell. Plant Physiol 147: 18001804.

Gregersen PL, Culetic A, Boschian L, Krupinska K (2013) Plant senescence and crop productivity. Plant Mol Biol 82: 603-622

Havé M, Marmagne A, Chardon F, Masclaux-Daubresse C (2017) Nitrogen remobilization during leaf senescence: lessons from Arabidopsis to crops. J Exp Bot 68: 2513-2529

Hensel LL, Grbić V, Baumgarten DA, Bleecker AB (1993) Developmental and age-related processes that influence the longevity and senescence of photosynthetic tissues in Arabidopsis. Plant Cell 5: 553-564

Hidema J, Makino A, Mae T, Ojima K (1991) Photosynthetic characteristics of rice leaves aged under different irradiances from full expansion through senescence. Plant Physiol 97: 1287-1293 
Hikosaka K (1996) Effects of leaf age, nitrogen nutrition and photon flux density on the organization of the photosynthetic apparatus in leaves of a vine (Ipomoea tricolor Cav.) grown horizontally to avoid mutual shading of leaves. Planta 198: 144-150

Hilditch PI, Thomas H, Thomas BJ, Rogers LJ (1989) Leaf senescence in a non-yellowing mutant of Festuca pratensis: Proteins of photosystem II. Planta 177: 265-272

Hirashima M, Satoh S, Tanaka R, Tanaka A (2006) Pigment shuffling in antenna systems achieved by expressing prokaryotic chlorophyllide $a$ oxygenase in Arabidopsis. J Biol Chem 281: 1538515393

Hobe S, Trostmann I, Raunser S, Paulsen H (2006) Assembly of the major light-harvesting chlorophyll-a/b complex - thermodynamics and kinetics of neoxanthin binding. J Biol Chem 281: $25156-25166$

Hodgkinson K (1974) Influence of partial defoliation on photosynthesis, photorespiration and transpiration by lucerne leaves of different ages. Funct Plant Biol 1: 561-578

Hollmann J, Gregersen PL, Krupinska K (2014) Identification of predominant genes involved in regulation and execution of senescence-associated nitrogen remobilization in flag leaves of field grown barley. J Exp Bot 65: 3963-3973

Hopkins M, Taylor C, Liu Z, Ma F, McNamara L, Wang T-W, Thompson JE (2007) Regulation and execution of molecular disassembly and catabolism during senescence. New Phytol 175: 201214

Horn R, Grundmann G, Paulsen H (2007) Consecutive binding of chlorophylls $a$ and $b$ during the assembly in vitro of light-harvesting chlorophyll-a/b protein (LHCIIb). J Mol Biol 366: 10451054

Hörtensteiner S, Feller U (2002) Nitrogen metabolism and remobilization during senescence. J Exp Bot 53: 927-937

Humbeck K, Krupinska K (1996) Does the Clp protease play a role during senescence-associated protein degradation in barley leaves? J Photochem Photobiol B: Biol 36: 321-326

Humbeck K, Krupinska K (2003) The abundance of minor chlorophyll $a / b$-binding proteins CP29 and LHCI of barley (Hordeum vulgare L.) during leaf senescence is controlled by light. J Exp Bot 54: $375-383$

Humbeck K, Quast S, Krupinska K (1996) Functional and molecular changes in the photosynthetic apparatus during senescence of flag leaves from field-grown barley plants. Plant Cell Environ 19: $337-344$ 
Ishida H, Izumi M, Wada S, Makino A (2014) Roles of autophagy in chloroplast recycling. Biochim Biophys Acta Bioenerg 1837: 512-521

Iwai M, Takizawa K, Tokutsu R, Okamuro A, Takahashi Y, Minagawa J (2010) Isolation of the elusive supercomplex that drives cyclic electron flow in photosynthesis. Nature 464: 12101213

Izumi M, Hidema J, Wada S, Kondo E, Kurusu T, Kuchitsu K, Makino A, Ishida H (2015) Establishment of monitoring methods for autophagy in rice reveals autophagic recycling of chloroplasts and root plastids during energy limitation. Plant Physiol 10.1104/pp.114.254078:

Izumi M, Nakamura S (2017) Vacuolar digestion of entire damaged chloroplasts in Arabidopsis thaliana is accomplished by chlorophagy. Autophagy 13: 1239-1240

Izumi M, Nakamura S (2018) Chloroplast protein turnover: The influence of extraplastidic processes, including autophagy. Int J Mol Sci 19: 828

Jajić I, Sarna T, Szewczyk G, Strzałka K (2015) Changes in production of reactive oxygen species in illuminated thylakoids isolated during development and senescence of barley. J Plant Physiol 184: 49-56

Jibran R, Sullivan KL, Crowhurst R, Erridge ZA, Chagné D, McLachlan ARG, Brummell DA,

Dijkwel PP, Hunter DA (2015) Staying green postharvest: how three mutations in the Arabidopsis chlorophyll $b$ reductase gene $N Y C 1$ delay degreening by distinct mechanisms. J Exp Bot 66: $6849-6862$

Juvany M, Müller M, Munné-Bosch S (2013) Photo-oxidative stress in emerging and senescing leaves: a mirror image? J Exp Bot 64: 3087-3098

Kambakam S, Bhattacharjee U, Petrich J, Rodermel S (2016) PTOX mediates novel pathways of electron transport in etioplasts of Arabidopsis. Mol Plant 9: 1240-1259

Kar M, Feierabend J (1984) Metabolism of activated oxygen in detached wheat and rye leaves and its relevance to the initiation of senescence. Planta 160: 385-391

Kato Y, Sugimoto K, Shikanai T (2018) NDH-PSI supercomplex assembly precedes full assembly of the NDH complex in chloroplast. Plant Physiol 176: 1728-1738

Keskitalo J, Bergquist G, Gardeström P, Jansson S (2005) A cellular timetable of autumn senescence. Plant Physiol 139: 1635-1648

Krieger-Liszkay A (2005) Singlet oxygen production in photosynthesis. J Exp Bot 56: 337-346 
Krieger-Liszkay A, Trösch M, Krupinska K (2015) Generation of reactive oxygen species in thylakoids from senescing flag leaves of the barley varieties Lomerit and Carina. Planta 241: $1497-1508$

Krupinska K, Humbeck K (2004) Photosynthesis and chloroplast breakdown, in Plant Cell Death Processes (Noodén LD ed), Academic Press, San Diego. pp 169-187

Krupinska K, Mulisch M, Hollmann J, Tokarz K, Zschiesche W, Kage H, Humbeck K, Bilger W

Kucharewicz W, Distelfeld A, Bilger W, Müller M, Munné-Bosch S, Hensel G, Krupinska K (2017) Acceleration of leaf senescence is slowed down in transgenic barley plants deficient in the DNA/RNA-binding protein WHIRLY1. J Exp Bot 68: 983-996

Kurepa J, Hérouart D, van Montagu M, Inzé D (1997) Differential expression of CuZn- and Fe-

Kusaba M, Ito H, Morita R, Iida S, Sato Y, Fujimoto M (2007) Rice NON-YELLOW COLORING1 is 763

Laloi C, Havaux M (2015) Key players of singlet oxygen-induced cell death in plants. Front Plant Sci 6: 39

Laloi C, Stachowiak M, Pers-Kamczyc E, Warzych E, Murgia I, Apel K (2007) Cross-talk between singlet oxygen- and hydrogen peroxide-dependent signaling of stress responses in Arabidopsis thaliana. Proc Natl Acad Sci USA 104: 672-677

Lennon AM, Prommeenate P, Nixon PJ (2003) Location, expression and orientation of the putative

Li L, Aro EM, Millar AH (2018) Mechanisms of photodamage and protein turnover in photoinhibition. Trends Plant Sci 23: 667-676

Li Z, Wakao S, Fischer BB, Niyogi KK (2009) Sensing and responding to excess light. Annu Rev Plant Biol 60: 239-260

Li H, Zheng Q, Zhang J, Li B, Li Z (2017) The analysis of determining factors and evaluation of tolerance to photoinhibition in wheat (Triticum aestivum L.). Photosynthetica 55: 69-76 
Ling Q, Huang W, Baldwin A, Jarvis P (2012) Chloroplast biogenesis is regulated by direct action of the ubiquitin-proteasome system. Science 338: 655-659

Majeran W, Wollman F-A, Vallon O (2000) Evidence for a role of ClpP in the degradation of the chloroplast cytochrome $b_{6} f$ complex. Plant Cell 12: 137-149

Makino A (2003) Rubisco and nitrogen relationships in rice: Leaf photosynthesis and plant growth. Soil Sci Plant Nutr 49: 319-327

Martínez DE, Costa ML, Guiamet JJ (2008) Senescence-associated degradation of chloroplast proteins inside and outside the organelle. Plant Biol 10: 15-22

Mehta RA, Fawcett TW, Porath D, Mattoo AK (1992) Oxidative stress causes rapid membrane translocation and in vivo degradation of ribulose-1,5-bisphosphate carboxylase/oxygenase. $\mathrm{J}$ Biol Chem 267: 2810-2816

Miao Y, Laun T, Zimmermann P, Zentgraf U (2004) Targets of the WRKY53 transcription factor and its role during leaf senescence in Arabidopsis. Plant Mol Biol 55: 853-867

Miersch I, Heise J, Zelmer I, Humbeck K (2000) Differential degradation of the photosynthetic apparatus during leaf senescence in barley (Hordeum vulgare L.). Plant Biology 2: 618-623

Miyake C, Asada K (1992) Thylakoid-bound ascorbate peroxidase in spinach chloroplasts and photoreduction of its primary oxidation product monodehydroascorbate radicals in thylakoids. Plant Cell Physiol 33: 541-553

Morris K, Mackerness SA, Page T, John CF, Murphy AM, Carr JP, Buchanan-Wollaston V (2000) Salicylic acid has a role in regulating gene expression during leaf senescence. Plant J 23: 677685

Moy A, Le S, Verhoeven A (2015) Different strategies for photoprotection during autumn senescence in maple and oak. Physiol Plant 155: 205-216

Mubarakshina MM, Ivanov BN (2010) The production and scavenging of reactive oxygen species in the plastoquinone pool of chloroplast thylakoid membranes. Physiol Plant 140: 103-110

Mulisch M, Krupinska K (2013) Ultrastructural analyses of senescence associated dismantling of chloroplasts revisited, in Plastid Development in Leaves during Growth and Senescence (Biswal B, Krupinska K, Biswal UC eds), Springer Netherlands, Dordrecht. p^pp 307-335

Murphy MP (2009) How mitochondria produce reactive oxygen species. Biochem J 417: 1-13

Nath K, Phee B-K, Jeong S, Lee SY, Tateno Y, Allakhverdiev SI, Lee C-H, Nam HG (2013) Agedependent changes in the functions and compositions of photosynthetic complexes in the thylakoid membranes of Arabidopsis thaliana. Photosynth Res 117: 547-556 
Nelson CJ, Alexova R, Jacoby RP, Millar AH (2014) Proteins with high turnover rate in barley leaves estimated by proteome analysis combined with in planta isotope labelling. Plant Physiol 166: 91-108

Nishimura K, Kato Y, Sakamoto W (2016) Chloroplast proteases: Updates on proteolysis within and across suborganellar compartments. Plant Physiol 171: 2280-2293

Noctor G, Foyer CH (1998) Ascorbate and glutathione: Keeping active oxygen under control. Annu Rev Plant Physiol Plant Mol Biol 49: 249-279

Ohe M, Rapolu M, Mieda T, Miyagawa Y, Yabuta Y, Yoshimura K, Shigeoka S (2005) Decline in leaf photooxidative-stress tolerance with age in tobacco. Plant Sci 168: 1487-1493

Park SY, Yu JW, Park JS, Li J, Yoo SC, Lee NY, Lee SK, Jeong SW, Seo HS, Koh HJ, Jeon JS, Park YI, Paek NC (2007) The senescence-induced staygreen protein regulates chlorophyll degradation. Plant Cell 19: 1649-1664

Pastori GM, del Rio LA (1997) Natural senescence of pea leaves (An activated oxygen-mediated function for peroxisomes). Plant Physiol 113: 411-418

Pesaresi P, Scharfenberg M, Weigel M, Granlund I, Schröder WP, Finazzi G, Rappaport F, Masiero S, Furini A, Jahns P, Leister D (2009) Mutants, overexpressors, and interactors of arabidopsis plastocyanin isoforms: Revised roles of plastocyanin in photosynthetic electron flow and thylakoid redox state. Mol Plant 2: 236-248

Pfannschmidt T, Munné-Bosch S (2013) Plastid signaling during the plant life cycle. In: Plastid development in leaves during growth and senescence (eds Biswal B, Krupinska K, Biswal UC), AIPR Series 36, Springer, pp 503-528

Pintó-Marijuan M, Munné-Bosch S (2014) Photo-oxidative stress markers as a measure of abiotic stress-induced leaf senescence: advantages and limitations. J Exp Bot 65: 3845-3857

Pogson BJ, Woo NS, Förster B, Small ID (2008) Plastid signalling to the nucleus and beyond. Trends Plant Sci. 13: 602-609

Pospíšil P, Arató A, Krieger-Liszkay A, Rutherford AW (2004) Hydroxyl radical generation by photosystem II. Biochemistry 43: 6783-6792

Procházková D, Wilhelmová N (2007) Leaf senescence and activities of the antioxidant enzymes. Biol Plant 51: 401-406

Ramel F, Birtic S, Ginies C, Soubigou-Taconnat L, Triantaphylidès C, Havaux M (2012) Carotenoid oxidation products are stress signals that mediate gene responses to singlet oxygen in plants. Proc Natl Acad Sci USA. 109: 535-540 
Renato M, Pateraki I, Boronat A, Azcón-Bieto J (2014) Tomato fruit chromoplasts behave as respiratory bioenergetic organelles during ripening. Plant Physiol 10.1104/pp.114.243931:

Rinalducci S, Pedersen JZ, Zolla L (2004) Formation of radicals from singlet oxygen produced during photoinhibition of isolated light-harvesting proteins of photosystem II. Biochim Biophys Acta Bioenerg 1608: 63-73

Roberts DR, Thompson JE, Dumbroff EB, Gepstein S, Mattoo AK (1987) Differential changes in the synthesis and steady-state levels of thylakoid proteins during bean leaf senescence. Plant Mol Biol 9: 343-353

Rutherford AW, Krieger-Liszkay A (2001) Herbicide-induced oxidative stress in photosystem II. Trends Biochem Sci 26: 648-653

Sabater B, Martín M (2013) Hypothesis: increase of the ratio singlet oxygen plus superoxide radical to hydrogen peroxide changes stress defense response to programmed leaf death. Front Plant Sci 4: 479

Sakuraba Y, Yokono M, Akimoto S, Tanaka R, Tanaka A (2010) Deregulated chlorophyll $b$ sythesis

Sakuraba Y, Schelbert S, Park SY, Han SH, Lee BD, Andrès CB, Kessler F, Hörtensteiner S, Paek NC

Sakuraba Y, Balazadeh S, Tanaka R, Mueller-Roeber B, Tanaka A (2012b) Overproduction of Chl $b$ retards senescence through transcriptional reprogramming in Arabidopsis. Plant Cell Physiol 53: 505-517

Schöttler MA, Kirchhoff H, Weis E (2004) The role of plastocyanin in the adjustment of the photosynthetic electron transport to the carbon metabolism in tobacco. Plant Physiol 136:

Schöttler MA, Tóth SZ (2014) Photosynthetic complex stoichiometry dynamics in higher plants: environmental acclimation and photosynthetic flux control. Front Plant Sci 5: 188 Ruf S, Bock R (2017) The plastid-encoded PsaI subunit stabilizes photosystem I during leaf senescence in tobacco. J Exp Bot 68: 1137-1155 
874

875

876

877

878

879

880

881

882

883

884

885

886

887

888

889

890

891

892

893

894

895

896

897

898

899

900

901

902

903

904

Seo M, Koshiba T (2011) Transport of ABA from the site of biosynthesis to the site of action. J Plant Res 124: 501-507

Stamp P, Herzog H (1976) Flag-leaf senescence and grain growth in certain German varieties of spring wheat (Triticum aestivum L.). Zeitschrift fuer Pflanzenzuechtung (Germany, FR):

Stoddart JL, Thomas H (1982) Leaf senescence, in Nucleic Acids and Proteins in Plants I: Structure, Biochemistry and Physiology of Proteins (Boulter D, Parthier B eds), Springer Berlin Heidelberg, Berlin, Heidelberg. $\mathrm{p}^{\wedge}$ pp 592-636

Stoy V (1963) The Translocation of C14-Labelled Photosynthetic Products from the Leaf to the Ear in Wheat. Physiol Plant 16: 851-866

Strand DD, Livingston AK, Satoh-Cruz M, Froehlich JE, Maurino VG, Kramer DM (2015) Activation of cyclic electron flow by hydrogen peroxide in vivo. Proc Nat Acad Sci 112: 5539-5544

Shumbe L, D'Alessandro S, Shao N, Chevalier A, Ksas B, Bock R, Havaux M (2017) METHYLENE BLUE SENSITIVITY 1 (MBS1) is required for acclimation of Arabidopsis to singlet oxygen and acts downstream of $\beta$-cyclocitral. Plant Cell Environ 40: 216-226

Swida-Barteczka A, Krieger-Liszkay A, Bilger W, Voigt UJ, Hensel G, Szweykowska-Kulinska Z, Krupinska K (2018) The plastid-nucleus located DNA/RNA binding protein WHIRLY1 regulates microRNA-levels during stress in barley (Hordeum vulgare L.). RNA Biol, DOI: $10.1080 / 15476286.1481695$

Szechynska-Hebda M, Karpinski S (2013) Light intensity-dependent retrograde signalling in higher plants. J Plant Physiol 170:1501-1516

Tallón C, Quiles MJ (2007) Acclimation to heat and high light intensity during the development of oat leaves increases the NADH DH complex and PTOX levels in chloroplasts. Plant Sci 173: 438445

Tanaka R, Tanaka A (2011) Chlorophyll cycle regulates the construction and destruction of the lightharvesting complexes. Biochim Biophys Acta Bioenerg 1807: 968-976

Tang Y, Wen X, Lu C (2005) Differential changes in degradation of chlorophyll-protein complexes of photosystem I and photosystem II during flag leaf senescence of rice. Plant Physiol Biochem 43: 193-201

Vanacker H, Sandalio LM, Jiménez A, Palma JM, Corpas FJ, Meseguer V, Gómez M, Sevilla F, Leterrier M, Foyer CH, del Río LA (2006) Roles for redox regulation in leaf senescence of pea plants grown on different sources of nitrogen nutrition. J Exp Bot 57: 1735-1745 
Voitsekhovskaja OV, Tyutereva EV (2015) Chlorophyll $b$ in angiosperms: Functions in photosynthesis, signaling and ontogenetic regulation. J Plant Physiol 189: 51-64

Wang F, Liu J, Chen M, Zhou L, Li Z, Zhao Q, Pan G, Zaidi S-H-R, Cheng F (2016) Involvement of abscisic acid in PSII photodamage and D1 protein turnover for light-induced premature senescence of rice flag leaves. PLOS ONE 11: e0161203

Wang J, Leister D, Bolle C (2015) Photosynthetic lesions can trigger accelerated senescence in Arabidopsis thaliana. J Exp Bot 66: 6891-6903

Woodson JD (2016) Chloroplast quality control - balancing energy production and stress. New Phytol 212: $36-41$

Wu P, Qian Y, Du P, Zhang H, Cai C (2012) Facile synthesis of nitrogen-doped graphene for measuring the releasing process of hydrogen peroxide from living cells. Journal of Materials Chemistry 22: 6402-6412

Xu YH, Liu R, Yan L, Liu ZQ, Jiang SC, Shen YY, Wang XF, Zhang DP (2012) Light-harvesting chlorophyll $a / b$-binding proteins are required for stomatal response to abscisic acid in Arabidopsis. J Exp Bot 63: 1095-1106

Yadav KNS, Semchonok DA, Nosek L, Kouřil R, Fucile G, Boekema E, Eichacker LA (2017) Supercomplexes of plant photosystem I with cytochrome $b_{6} f$, light-harvesting complex II and NDH. Biochim Biophys Acta Bioenerg 1858: 12-20

Yalpani N, Enyedi AJ, Leon J, Raskin I (1994) Ultraviolet-light and ozone stimulate accumulation of salicylic-acid, pathogenesis-related proteins and virus-resistance in tobacco. Planta 193: 372376

Yamazaki J-y, Kamimura Y, Okada M, Sugimura Y (1999) Changes in photosynthetic characteristics and photosystem stoichiometries in the lower leaves in rice seedlings. Plant Sci 148: 155-163

Yoo SD, Greer DH, Laing WA, McManus MT (2003) Changes in photosynthetic efficiency and carotenoid composition in leaves of white clover at different developmental stages. Plant Physiol Biochem 41: 887-893

Yu Q, Feilke K, Krieger-Liszkay A, Beyer P (2014) Functional and molecular characterization of plastid terminal oxidase from rice (Oryza sativa). Biochim Biophys Acta Bioenerg 1837: $1284-1292$

Zapata JM, Guéra A, Esteban-Carrasco A, Martín M, Sabater B (2005) Chloroplasts regulate leaf senescence: delayed senescence in transgenic $n d h F$-defective tobacco. Cell Death Differ 12: 1277 
937 Zentgraf U, Zimmermann P, Smykowski A (2012) Role of intracellular hydrogen peroxide as 938 signalling molecule for plant senescence, in Senescence, InTech. $\mathrm{p}^{\wedge} \mathrm{pp}$

939 Zimmermann P, Heinlein C, Orendi G, Zentgraf U (2006) Senescence-specific regulation of catalases 940 in Arabidopsis thaliana (L.) Heynh. Plant Cell Environ 29: 1049-1060

941 Zimmermann P, Zentgraf U (2005) The correlation between oxidative stress and leaf senescence 942 during plant development. Cell Mol Biol Lett 10: 515

943 


\section{Figure Legends}

945 Fig. 1.

946 Photosynthetic electron transport system in $C_{3}$ plants. (A) Overview of photosynthetic linear electron

947 flow (dashed red arrow). Electrons from $\mathrm{H}_{2} \mathrm{O}$ are transported from photosystem II (PSII) to

948 photosystem I (PSI) via plastoquinone (PQ) pool, cytochrome (Cyt) $b_{6} / f$ complex and plastocyanin,

949 generating NADPH. Coupled with electron transport a proton gradient is built up that is used to

950 produce ATP. (B) Overview showing three different alternative electron transport pathways: (1) cyclic

951 electron flow via the protein Proton Gradient Regulation 5 (PGR5) and PGR5-like protein 1 (PGRL1;

952 dashed pink arrow); (2) via chloroplast $\mathrm{NAD}(\mathrm{P}) \mathrm{H}$ dehydrogenase (NDH) complex (dashed purple

953 arrow); and (3) chlororespiration through NDH complex and plastidial terminal oxidase (PTOX;

954 dashed green arrow). Dashed blue arrows indicate the transport of protons. The other abbreviations are

955 shown as follows: LHCII, light-harvesting complex in PSII; Fd, ferredoxin; FNR, Fd-NADP ${ }^{+}$

956 reductase; CBB cycle, the Calvin-Benson cycle; ATPase, chloroplast ATP synthase.

957

$958 \quad$ Fig. 2

959 Hypothetical alternative electron transport pathways in senescing leaves. (A) Photosynthetic linear

960 electron flow in non-senescing leaves. (B) Cyclic electron flow around photosystem I (PSI) in

961 senescing leaves with few or no photosystem II (PSII). (C) $\mathrm{O}_{2}$-dependent alternative electron transport

962 via plastidial terminal oxidase (PTOX) in senescing leaves with few or no PSI. (D) Chlororespiration

963 via chloroplast NAD(P)H dehydrogenase (NDH) complex and PTOX in senescing leaves with few or

964 no PSII and PSI. Red and blue arrows indicate the electron and proton transport, respectively. The

965 other abbreviations are shown as follows: $\mathrm{PQ}$, plastoquinone; Cyt $b_{6} / f$, cytochrome $b_{6} / f$ complex;

966 ATPase, chloroplast ATP synthase 

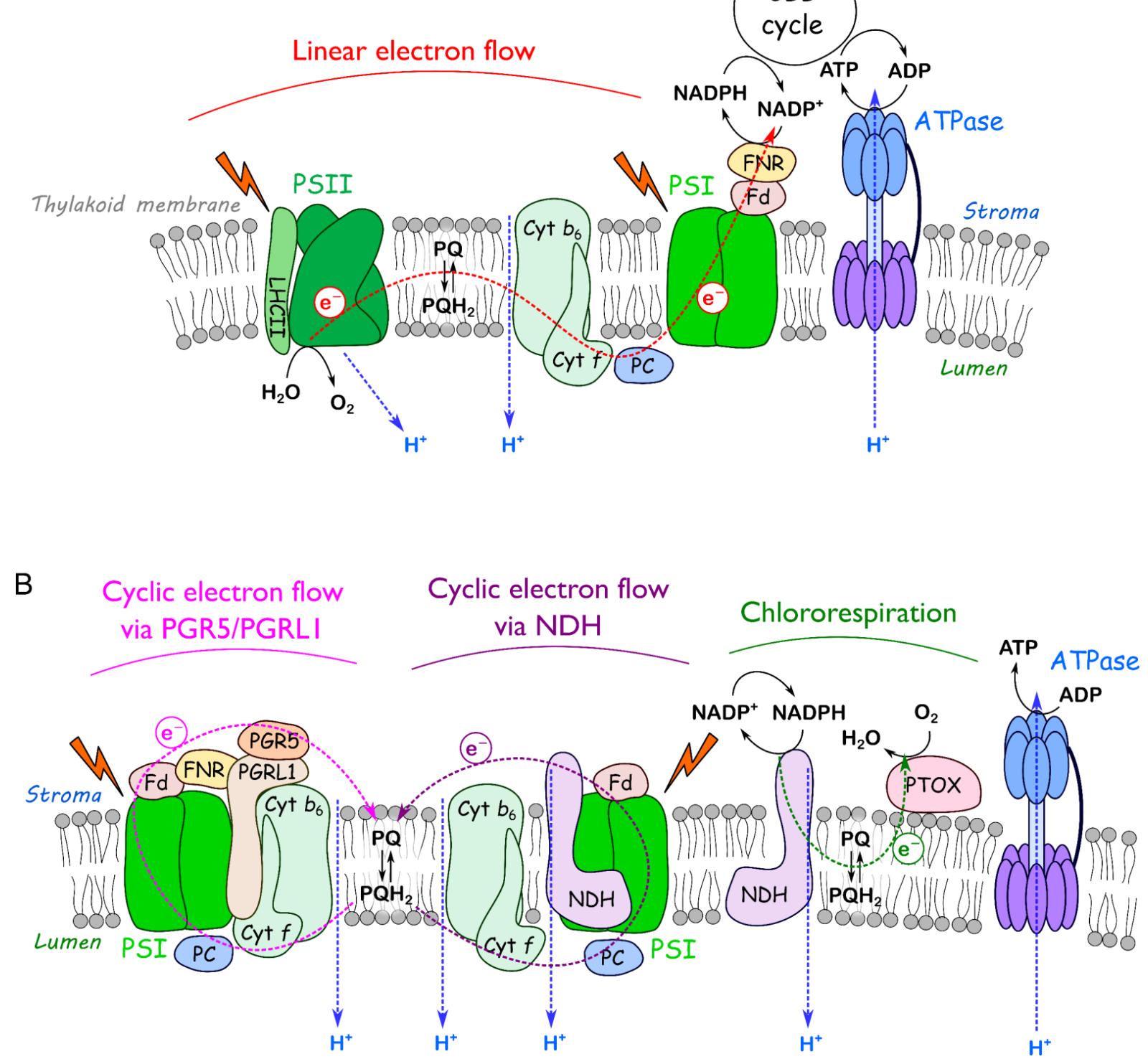

Fig. 1. Photosynthetic electron transport system in $\mathrm{C}_{3}$ plants. (A) Overview of photosynthetic linear electron flow (dashed red arrow). Electrons from $\mathrm{H}_{2} \mathrm{O}$ are transported from photosystem II (PSII) to photosystem I (PSI) via plastoquinone (PQ) pool, cytochrome (Cyt) $b_{6} / f$ complex and plastocyanin, generating NADPH. Coupled with electron transport a proton gradient is built up that is used to produce ATP. (B) Overview showing three different alternative electron transport pathways: (1) cyclic electron flow via the protein Proton Gradient Regulation 5 (PGR5) and PGR5-like protein 1 (PGRL1; dashed pink arrow); (2) via chloroplast NAD(P)H dehydrogenase (NDH) complex (dashed purple arrow); and (3) chlororespiration through NDH complex and plastidial terminal oxidase (PTOX; dashed green arrow). Dashed blue arrows indicate the transport of protons. The other abbreviations are shown as follows: LHCII, light-harvesting complex in PSII; Fd, ferredoxin; FNR, Fd-NADP $^{+}$reductase; CBB cycle, the Calvin-Benson cycle; ATPase, chloroplast ATP synthase. 

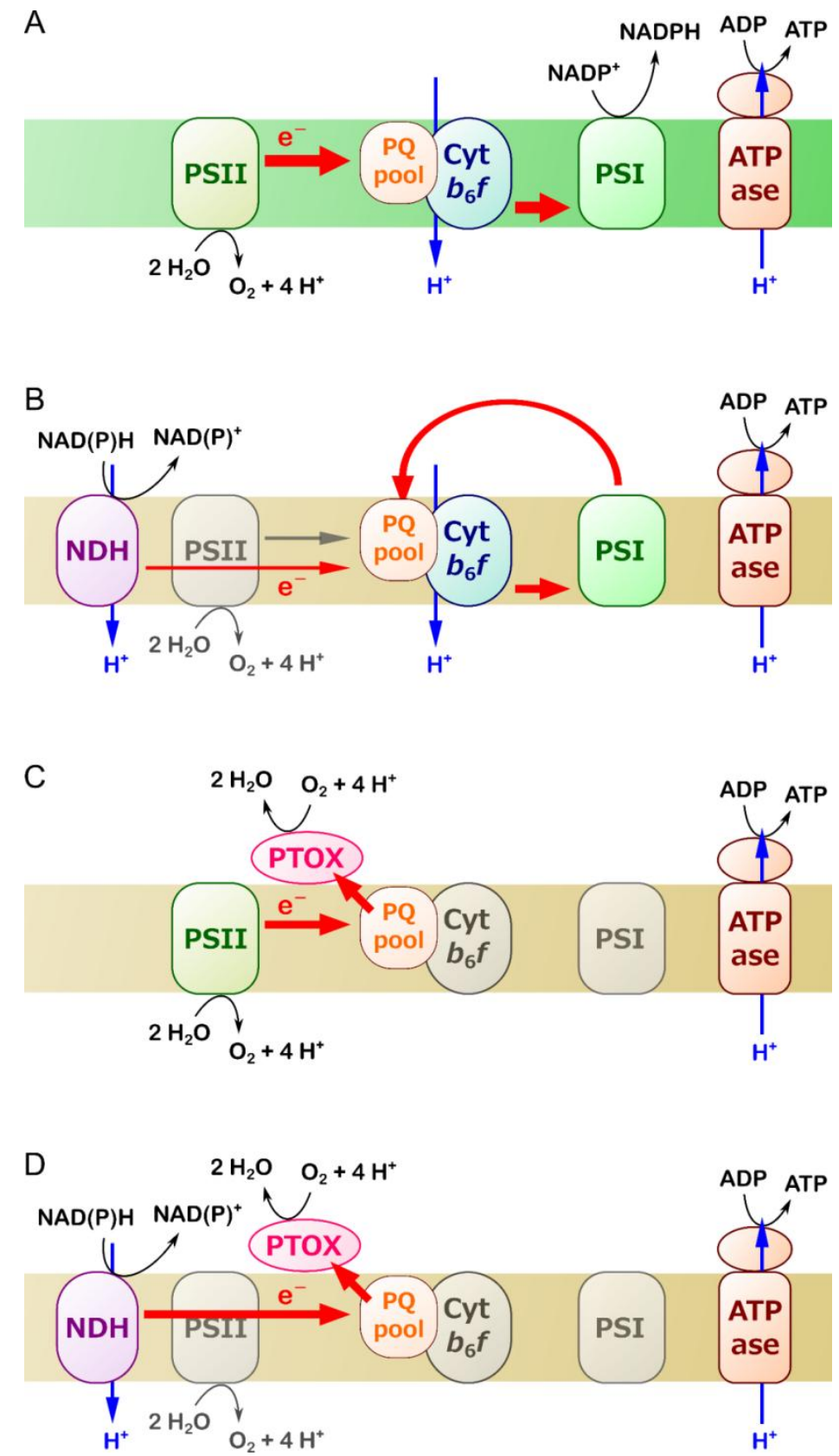

Fig. 2. Hypothetical alternative electron transport pathways in senescing leaves. (A) Photosynthetic linear electron flow in non-senescing leaves. (B) Cyclic electron flow around photosystem I (PSI) in senescing leaves with few or no photosystem II (PSII). (C) $\mathrm{O}_{2}$-dependent alternative electron transport via plastidial terminal oxidase (PTOX) in senescing leaves with few or no PSI. (D) Chlororespiration via chloroplast NAD(P)H dehydrogenase (NDH) complex and PTOX in senescing leaves with few or no PSII and PSI. Red and blue arrows indicate the electron and proton transport, respectively. The other abbreviations are shown as follows: PQ, plastoquinone; Cyt $b_{6} / f$, cytochrome $b_{6} / f$ complex; ATPase, chloroplast ATP synthase. 